This is the final peer-reviewed accepted manuscript of:

Borghetti, Alberto, Fabio Napolitano, and Carlo Alberto Nucci. "Volt/var Optimization of Unbalanced Distribution Feeders via Mixed Integer Linear Programming." International Journal of Electrical Power \& Energy Systems 72 (2015): 40-47.

The final published version is available online at:

https://doi.org/10.1016/j.ijepes.2015.02.009

Rights / License:

The terms and conditions for the reuse of this version of the manuscript are specified in the publishing policy. For all terms of use and more information see the publisher's website.

This item was downloaded from IRIS Università di Bologna (https://cris.unibo.it/)

When citing, please refer to the published version. 


\title{
Volt/Var Optimization of Unbalanced Distribution Feeders via Mixed Integer Linear Programming
}

\author{
Alberto Borghetti $^{\mathrm{a}}$, Fabio Napolitano ${ }^{\mathrm{a}}$, Carlo Alberto Nucci $^{\mathrm{a}}$ \\ ${ }^{a}$ University of Bologna, Italy \\ *Corresponding author. E-mail address: alberto.borghetti@unibo.it. \\ Tel. +39051209 3475. Fax: +390512093470
}

\begin{abstract}
The paper presents a Mixed Integer Linear Programming (MILP) model for the solution of the threephase volt/var optimization (VVO) of medium voltage unbalanced distribution feeders. The VVO of a distribution feeder is aimed at calculating the most efficient operating conditions by means of the scheduling of transformers equipped with an on-load tap changer and distributed reactive power resources (such as embedded generators and switchable capacitors banks). The proposed model allows the representation of feeders composed by three-phase, two-phase, and single-phase lines, by transformers with different winding connections, by unbalanced wye- and delta-connected loads, by three-phase and single phase capacitor banks and embedded generators. The accuracy of the results is verified by using IEEE Test Feeders.
\end{abstract}

\section{Keywords}

Power distribution feeders, Unbalanced networks, Volt/var optimization, Mixed integer linear programming. 


\section{Introduction}

One of the active network management functions that modern distribution management systems are expected to provide is the so-called volt/var optimization (VVO) [1][2].

Different VVO definitions have been used in the technical literature. In general VVO problem refers to the determination of the set points of on-load tap changers (OLTCs) and switchable capacitor banks regulators with the objective of loss minimization or load reduction, taking into account the usual operating constraints such as minimum and maximum voltage limits and ampacity (e.g. [3]). Modern and future distribution networks also require the optimization of the reactive power compensation capabilities provided by embedded generators (EGs) and by storage systems, with particular reference to those equipped by power electronic converters such as photovoltaic inverters (e.g. [4], [5] and references therein).

The typical differences between the VVO in distribution networks and the optimal power flow (OPF) problem in transmission systems are:

- usually VVO does not involve generator active power outputs as control variables, since EG outputs are mainly determined by the availability of energy resources and market/regulatory constraints;

- the main VVO control variables are integer (transformer taps and capacitor switching), whilst typical OPF control variables are continuous;

- voltage limits are usually more stringent than ampacity constraints;

- line and load unbalances appear in general more significant in distribution feeders than in transmission networks (this justifies the modelling effort in order to represent all the three phases of the system [6]).

Moreover, with respect to transmission system lines, distribution feeders are characterized by shorter length, higher ratio between resistance and reactance of the longitudinal impedance, and they are expected to transmit lower power flows. Therefore the influence of active power flows to voltage profile is not negligible and, usually, the maximum phase difference between the voltages at a bus in different operating conditions is limited to few degrees. On the other hand VVO shares several 
aspects and solution approaches with OPF, so to justify the definition of distribution optimal power flow (DOPF) models (e.g. [7]).

This paper aims at describing a Mixed Integer Linear Programming (MILP) model for the solution of the deterministic VVO of unbalanced distribution feeders. As reviewed in [8], among the various approaches described in the literature, the use of mixed integer linear programming (MILP) appears to have been less explored than other approaches for the solution of VVO problems. The motivation of using a MILP approach for VVO lays mainly on the availability of efficient solvers for this class of problems [9]. This approach has been recently investigated not only for distribution networks (e.g. [10]-[13]) but also for the solution of the classical OPF problem in transmission systems (e.g. [14], [15]).

The proposed model is a development of the one presented in [8] based on the representation of the distribution network with voltage - current relationships in Cartesian coordinates. The linear representation of loads and EGs is based on the assumption of limited deviations of bus voltage phasors with respect to the corresponding rated phasors. The MILP formulation presented in [8] assumes that the network is balanced. This paper presents a MILP model for a generic unbalanced distribution feeder, taking into account the different types of transformer winding connections, wyeand delta-connected loads, the presence of single-phase and three-phase EGs as well as the possibility to switch the capacitors on a per phase basis. The unbalanced per phase model is based on the representation of both lines and transformers with an equivalent network of uncoupled branches [16]. As in [8] the configuration of the feeder is assumed known and it is not changed. The developed MILP model determines the optimal solution only for the current time. Time coupling constraints, with particular reference to the maximum number of transformers tap changes and on/off switching cycles of capacitor banks, are not included. They would require an optimal schedule for the entire day (e.g., [2], [7]). If the optimization horizon is larger than some tens of minutes, several uncertainties relevant to both renewable generators outputs and loads levels need to be taken into account (see, for example, [17]).

As expected, the required computational effort is significantly increased with respect to the equivalent single phase model presented in [8]. 
The structure of the paper is the following. Section 2 presents the main characteristics of the implemented MILP model and the complete model formalization. Section 3 illustrates the performances by the results obtained for some IEEE test feeders [18] with additional EGs. Section 4 concludes the paper.

\section{Description of the optimization problem}

This section presents the implemented formulation of the MILP model. The network has $N / 3$ threephase buses each composed by 3 nodes plus a slack bus (that represents the HV bus of the HV/MV substation) also composed by 3 nodes. The network has $N_{b}$ uncoupled branches and it is composed by the equivalent networks of the lines or transformers described in one of the following subsections. Voltages of each node and the currents of each branch are represented by the Cartesian coordinates of their phasors $\left(V^{\mathrm{re}}, V^{\mathrm{im}}\right)$ and $\left(I^{\mathrm{re}}, I^{\mathrm{im}}\right)$, respectively. Voltage phasors at the nodes of the slack bus have modulus equal to the rated value and phases so that to form a three-phase symmetrical system. All the equations are written in per unit (pu).

\subsection{Objective function}

As in [8], the considered deterministic static VVO aims at minimizing the active power consumption from the transmission network (and maximizing the active power injection), whilst minimizing the violation of the minimum and maximum voltage limits at all the buses and the violation of a minimum power factor constraint enforced for each phase at the slack bus:

$$
\min \left\{\sum_{k_{s}=1}^{3} P_{k_{s}}+w_{\min } \sum_{k=1}^{N} \chi_{k}^{\min }+w_{\max } \sum_{k=1}^{N} \chi_{k}^{\max }+w_{\mathrm{pf}} \sum_{k_{s}=1}^{3} \chi_{k_{s}}^{\mathrm{pf}}\right\}
$$

where $P_{k_{s}}$ is the active power absorbed from the HV external network through node $k_{s}$ of the slack bus, $\chi_{k}^{\min }$ and $\chi_{k}^{\max }$ indicate the violations of the minimum and maximum voltage bounds at node $k$,

respectively, $w_{\min }$ and $w_{\max }$ are the weights that penalize the corresponding violations, $\chi_{k_{s}}^{\mathrm{pf}}$ indicates the violation of the minimum power factor at node $k_{s}$ of the slack bus and $w_{\mathrm{pf}}$ the relevant penalizing weight. 
For each node $k, \chi_{k}^{\min }$ and $\chi_{k}^{\max }$ are provided by a piecewise linear function (PLF) of the square of the voltage violation. The set of constraints that define the PLF are the following

$$
-\chi_{k}^{\min }+\lambda_{i}^{\Delta V} \Delta V_{k}^{\min } \leq-\Lambda_{i}^{\Delta V} \quad \text { and }-\chi_{k}^{\max }+\lambda_{i}^{\Delta V} \Delta V_{k}^{\max } \leq-\Lambda_{i}^{\Delta V} \quad \forall i=1 \ldots \bar{z}_{\Delta V}-1
$$

where $\Delta V_{k}^{\min }$ and $\Delta V_{k}^{\max }$ are the non-negative continuous variables that correspond to the absolute value of the voltage violations of the minimum or maximum limits at node $k$ (i.e., $V_{k}^{\min }$ and $V_{k}^{\max }$ ), respectively; $\lambda_{i}^{\Delta V}$ is the slope and $\Lambda_{i}^{\Delta V}$ is the ordinate intercept of PLF interval $i$; $\bar{z}_{\Delta V}$ is the number of PLF breakpoints.

Slope $\lambda_{i}^{\Delta V}$ and ordinate intercept $\Lambda_{i}^{\Delta V}$ are calculated as:

$$
\lambda_{i}^{\Delta V}=\Delta V_{i+1}+\Delta V_{i}, \quad \Lambda_{i}^{\Delta V}=\Delta V_{i}^{2}-\lambda_{i}^{\Delta V} \Delta V_{i} \quad \forall i=1 \ldots \bar{z}_{\Delta V}-1
$$

For node $k_{s}$ corresponding to one the three phases of the slack bus, $\chi_{k_{s}}^{\mathrm{pf}}$ is obtained by the following inequality constraint

$$
\left|Q_{k_{s}}\right|-\tan \left(\cos ^{-1}\left(p f_{\min }\right)\right)\left|P_{k_{s}}\right|-\chi_{k_{s}}^{\mathrm{pf}} \leq 0
$$

where $Q_{k_{s}}$ is the reactive power abortion from the HV external network through node $k_{s}$ of the slack bus and $p f_{\min }$ is the power factor minimum operating value. $P_{k_{s}}$ and $Q_{k_{s}}$ value are linked with the currents in the branches connected to node $k_{s}$ by the following equality constraints

$$
\begin{aligned}
& P_{k_{s}}-\sum_{b_{s} \in B_{s}} V_{k_{s}}^{r e} I_{b_{s}}^{r e}-\sum_{b_{s} \in B_{s}} V_{k_{s}}^{i m} I_{b_{s}}^{i m}=0 \\
& Q_{k_{s}}+\sum_{b_{s} \in B_{s}} V_{k_{s}}^{r e} I_{b_{s}}^{i m}-\sum_{b \in B_{s}} V_{k_{s}}^{i m} I_{b_{s}}^{r e}=0
\end{aligned}
$$

where $V_{k_{s}}$ is the fixed voltage phasor at node $k_{s}, B_{\mathrm{s}}$ is the set of branches $b_{\mathrm{s}}$ connected to node $k_{s}$ of the slack bus and $I_{b_{s}}$ is the current in branch $b_{s}$. Absolute values $\left|P_{k_{s}}\right|$ and $\left|Q_{k_{s}}\right|$ are obtained by

$$
\begin{array}{lll}
\left|P_{k_{s}}\right|-\Delta P_{k_{s}}^{+}-P_{k_{s}}=0 & \text { and } & \left|Q_{k_{s}}\right|-\Delta Q_{k_{s}}^{+}-Q_{k_{s}}=0 \\
\Delta P_{k_{s}}^{+}+M_{k_{s}}^{P} w_{k_{s}}^{P} \leq M_{k_{s}}^{P} & \text { and } & \Delta Q_{k_{s}}^{+}+M_{k_{s}}^{Q} w_{k_{s}}^{Q} \leq M_{k_{s}}^{Q} \\
-\left|P_{k_{s}}\right|+\Delta P_{k_{s}}^{-}-P_{k_{s}}=0 & \text { and } & -\left|Q_{k_{s}}\right|+\Delta Q_{k_{s}}^{-}-Q_{k_{s}}=0 \\
\Delta P_{k_{s}}^{-}-M_{k_{s}}^{P} w_{k_{s}}^{P} \leq 0 & \text { and } & \Delta Q_{k_{s}}^{-}-M_{k_{s}}^{Q} w_{k_{s}}^{Q} \leq 0
\end{array}
$$


where $\Delta P_{k_{s}}^{-}, \Delta P_{k_{s}}^{+}, \Delta Q_{k_{s}}^{-}, \Delta Q_{k_{s}}^{+}$are non-negative continuous variables, $w_{k_{s}}^{P}$ and $w_{k_{s}}^{Q}$ are binary variables, and $M_{k_{s}}^{P}$ and $M_{k_{s}}^{Q}$ are tight big values.

As in [8], other than those shown in (1), the objective function includes additional terms that allow the penalized disconnection of loads and EGs by means of binary variables if it is needed to find a feasible solution.

\subsection{Branch equations}

The equivalent representation as a network of uncoupled branches for both lines and transformers (with various types of winding connections) have been presented in several papers (e.g. [16], [19]-[21]). Here below we review the models used in this paper to obtain the test results.

The three-phase line data are the impedance and susceptance $3 \times 3$ symmetrical matrices $(\mathbf{Z}$ and $\mathbf{B})$. Analogously to three-phase lines, the input data for two-phase and single-phase lines are represented by $2 \times 2$ matrices and two complex numbers, respectively. The input data of the transformers are the longitudinal resistance $r_{t}$, longitudinal reactance $x_{t}$, shunt admittance $y_{0}$ and ratio $m$ (tap position at primary side is assumed fixed at nominal position). Tables I, II and III show the equations used to obtain the branch admittances for the case of a three-phase line, a grounded wye - grounded wye transformer and a delta - grounded wye transformer, respectively. A, B, C, and grounded node $\mathrm{N}$ identify the sending termination, whilst the corresponding lower case letters are used for the receiving termination.

Each branch from node $h$ to $k$ with admittance $y_{b}$ is associated to two linear constraints

$$
\begin{aligned}
& V_{h}^{r e}-V_{k}^{r e}-r_{b, t} I_{b, t}^{r e}+x_{b, t} I_{b, t}^{i m}+\Delta v_{b, t}^{r e}=0 \\
& V_{h}^{i m}-V_{k}^{i m}-x_{b, t} I_{b, t}^{r e}-r_{b, t} I_{b, t}^{i m}+\Delta v_{b, t}^{i m}=0
\end{aligned}
$$

where $r_{b, t}+j x_{b, t}=y_{b, t}^{-1}$ that for the case of transformers equipped with an OLTC depends on tap position $t$. Each tap position $t$ is associated to auxiliary variables $\Delta v_{b, t}^{r e}$ and $\Delta v_{b, t}^{i m}$. If $t$ is the selected tap position, $\Delta v_{b, t}^{r e}$ and $\Delta v_{b, t}^{i m}$ are forced to be null by the following constraints, otherwise their value adapt to the voltage difference between the transformer terminals. 
$\forall t=1 \ldots n_{b, t}:$

$$
\begin{aligned}
& \Delta v_{b, t}^{r e}+M_{b}^{r e} u_{b, t} \leq M_{b}^{r e} \text { and }-\Delta v_{b, t}^{r e}+M_{b}^{r e} u_{b, t} \leq M_{b}^{r e} \\
& \Delta v_{b, t}^{i m}+M_{b}^{i m} u_{b, t} \leq M_{b}^{i m} \text { and }-\Delta v_{b, t}^{i m}+M_{b}^{i m} u_{b, t} \leq M_{b}^{i m} \\
& -I_{b}^{\max } u_{b, t} \leq I_{b, t}^{r e} \leq I_{b}^{\max } u_{b, t} \text { and }-I_{b}^{\max } u_{b, t} \leq I_{b, t}^{i m} \leq I_{b}^{\max } u_{b, t}
\end{aligned}
$$

and

$$
\sum_{t=1}^{n_{b, t}} u_{b, t}=1, I_{b}^{r e}-\sum_{t=1}^{n_{b, t}} I_{b, t}^{r e}=0, I_{b}^{i m}-\sum_{t=1}^{n_{b, t}} I_{b, t}^{i m}=0
$$

where $u_{b, t}$ is a binary variable associated to each tap position $t, n_{b, t}$ is the total number of tap positions and $I_{b}^{\max }$ is the maximum feasible value of $\left|I_{b}\right| \cdot M_{b}^{r e}$ and $M_{b}^{i m}$ are tight but sufficiently large values that do not limit $\Delta v_{b, t}^{r e}$ and $\Delta v_{b, t}^{i m}$ when $u_{b, t}=0$.

For branches not associated to variable tap changers (e.g. lines and fixed ratio transformers), (8) simplifies being $I_{b, t}^{r e}=I_{b}^{r e}, I_{b, t}^{i m}=I_{b}^{i m}$ and $\Delta v_{b, t}^{r e}=0, \Delta v_{b, t}^{i m}=0$.

\subsection{Load Model}

Both wye- and delta-connected loads are represented. For the case of wye-connected loads, the voltage of the neutral is assumed to be 0 and the load current is assumed positive if drained from the phase node. If the load is delta connected, the positive load current is drained from one node (node $k$ in the following equations) and injected into a second node (node $h$ ).

Each load is represented by a weighted combination of constant impedance, constant current, and constant power components (ZIP model):

$$
\begin{aligned}
& P_{\mathrm{L}, k}=P_{\mathrm{L}, k}^{0}\left[a_{\mathrm{P}, k}\left|\frac{V_{k}}{V_{0, k}}\right|^{2}+b_{\mathrm{P}, k}\left|\frac{V_{k}}{V_{0, k}}\right|+c_{\mathrm{P}, k}\right] \\
& Q_{\mathrm{L}, k}=Q_{\mathrm{L}, k}^{0}\left[a_{\mathrm{Q}, k}\left|\frac{V_{k}}{V_{0, k}}\right|^{2}+b_{\mathrm{Q}, k}\left|\frac{V_{k}}{V_{0, k}}\right|+c_{\mathrm{Q}, k}\right]
\end{aligned}
$$


where the coefficients satisfy the condition $a_{\mathrm{P}, k}+b_{\mathrm{P}, k}+c_{\mathrm{P}, k}=a_{\mathrm{Q}, k}+b_{\mathrm{Q}, k}+c_{\mathrm{Q}, k}=1$ and $P_{\mathrm{L}, k}^{0}, Q_{\mathrm{L}, k}^{0}$ are the real and reactive power consumed at note $k$ with rated voltage $V_{0, k}=\left|V_{0, k}\right| e^{j \angle V_{k}^{0}}$ corresponding to a three-phase symmetrical system.

Cartesian coordinates $I_{\mathrm{L}, k}^{r e}$ and $I_{\mathrm{L}, k}^{i m}$ of the load current are defined by

$$
\begin{aligned}
& I_{\mathrm{L}, k}^{r e}-I_{\mathrm{L}, k}^{\mathrm{Z}, r e}-\Delta I_{\mathrm{L}, k}^{\mathrm{I}, r e}-\Delta I_{\mathrm{L}, k}^{\mathrm{P}, r e}=\operatorname{In}_{k}^{\mathrm{P}, r e}+\operatorname{In}_{k}^{\mathrm{I}, r e} \\
& I_{\mathrm{L}, k}^{i m}-I_{\mathrm{L}, k}^{\mathrm{Z}, i m}-\Delta I_{\mathrm{L}, k}^{\mathrm{I}, i m}-\Delta I_{\mathrm{L}, k}^{\mathrm{P}, i m}=\operatorname{In}_{k}^{\mathrm{P}, i m}+\operatorname{In}_{k}^{\mathrm{I}, i m}
\end{aligned}
$$

where $\operatorname{In}_{k}^{\mathrm{I}, r e}+j \operatorname{In}_{k}^{\mathrm{I}, i m}=b_{\mathrm{P}, k} P_{\mathrm{L}, k}^{0}-j b_{Q, k} Q_{\mathrm{L}, k}^{0}$ at $V_{0, k}$ and $\operatorname{In}_{k}^{\mathrm{P}, r e}+j \operatorname{In}_{k}^{\mathrm{P}, i m}=c_{\mathrm{P}, k} P_{\mathrm{L}, k}^{0}-j c_{Q, k} Q_{\mathrm{L}, k}^{0}$ at $V_{0, k}$, whilst $I_{\mathrm{L}, k}^{\mathrm{Z}, r e}, I_{\mathrm{L}, k}^{\mathrm{Z}, \mathrm{im}}$ represent the current drawn by a constant impedance load (with admittance

$$
\begin{aligned}
Y_{\mathrm{L}, k}=G_{\mathrm{L}, k}+j B_{\mathrm{L}, k}=a_{\mathrm{P}, k} & \left.P_{\mathrm{L}, k}^{0}-j a_{\mathrm{Q}, k} Q_{\mathrm{L}, k}^{0}\right): \\
& I_{\mathrm{L}, k}^{\mathrm{Z}, r e}-G_{\mathrm{L}, k}\left(V_{k}^{r e}-V_{h}^{r e}\right)+B_{\mathrm{L}, k}\left(V_{k}^{i m}-V_{h}^{r e}\right)=0 \\
& I_{\mathrm{L}, k}^{\mathrm{Z}, m}-G_{\mathrm{L}, k}\left(V_{k}^{i m}-V_{h}^{i m}\right)-B_{\mathrm{L}, k}\left(V_{k}^{r e}-V_{h}^{r e}\right)=0
\end{aligned}
$$

In (12) $\Delta I_{\mathrm{L}, k}^{\mathrm{I} r e}, \Delta I_{\mathrm{L}, k}^{\mathrm{I}, i m}, \Delta I_{\mathrm{L}, k}^{\mathrm{P}, r e}, \Delta I_{\mathrm{L}, k}^{\mathrm{P}, i m}$ represent the variations of the current components relevant to the constant current model and constant power model due to the variation of the bus voltage, as defined by the following constraints. The implemented linear representation is based on the assumption of small bus-voltage deviations with respect to $V_{0, k}$.

For $\Delta I_{\mathrm{L}, k}^{\mathrm{I}, r e}$ and $\Delta I_{\mathrm{L}, k}^{\mathrm{I}, i m}$ we write

$$
\begin{gathered}
\Delta I_{\mathrm{L}, k}^{\mathrm{I}, r e}+\frac{\left|\operatorname{In}_{k}^{\mathrm{I}}\right|}{k_{1}\left|V_{0, k}\right|} \sin \left(\angle \operatorname{In}_{k}^{\mathrm{I}}\right)\left[\left(\Delta V_{k}^{i m}-\Delta V_{h}^{i m}\right) \cos \left(\angle V_{k}^{0}+k_{2}\right)-\right. \\
\left.-\left(\Delta V_{k}^{r e}-\Delta V_{h}^{r e}\right) \sin \left(\angle V_{k}^{0}+k_{2}\right)\right]=0 \\
\Delta I_{\mathrm{L}, k}^{\mathrm{I}, i m}-\frac{\left|I_{k}^{\mathrm{I}}\right|}{k_{1}\left|V_{0, k}\right|} \cos \left(\angle \operatorname{In}_{k}^{\mathrm{I}}\right)\left[\left(\Delta V_{k}^{i m}-\Delta V_{h}^{i m}\right) \cos \left(\angle V_{k}^{0}+k_{2}\right)-\right. \\
\left.-\left(\Delta V_{k}^{r e}-\Delta V_{h}^{r e}\right) \sin \left(\angle V_{k}^{0}+k_{2}\right)\right]=0
\end{gathered}
$$

where $k_{1}=\sqrt{3}$ and $k_{2}=\pi / 6$ if the load is delta connected, otherwise they are 1 and 0 respectively. Analogously, for $\Delta I_{\mathrm{L}, k}^{\mathrm{P}, r e}$ and $\Delta I_{\mathrm{L}, k}^{\mathrm{P}, i m}$ : 


$$
\begin{aligned}
& \Delta I_{\mathrm{L}, k}^{\mathrm{P}, r e} k_{1}\left|V_{0, k}\right| \cos \left(\angle V_{k}^{0}+k_{2}\right)+\Delta I_{\mathrm{L}, k}^{\mathrm{P}, i m} k_{1}\left|V_{0, k}\right| \sin \left(\angle V_{k}^{0}+k_{2}\right)+ \\
& +\operatorname{In}_{k}^{\mathrm{P}, r e}\left(\Delta V_{k}^{r e}-\Delta V_{h}^{r e}\right)+\operatorname{In}_{k}^{\mathrm{P}, i m}\left(\Delta V_{k}^{i m}-\Delta V_{h}^{i m}\right)=0 \\
& \Delta I_{\mathrm{L}, k}^{\mathrm{P}, r e} k_{1}\left|V_{0, k}\right| \sin \left(\angle V_{k}^{0}+k_{2}\right)-\Delta I_{\mathrm{L}, k}^{\mathrm{P}, i m} k_{1}\left|V_{0, k}\right| \cos \left(\angle V_{k}^{0}+k_{2}\right)+ \\
& +\operatorname{In}_{k}^{\mathrm{P}, r e}\left(\Delta V_{k}^{i m}-\Delta V_{h}^{i m}\right)-\operatorname{In}_{k}^{\mathrm{P}, i m}\left(\Delta V_{k}^{r e}-\Delta V_{h}^{r e}\right)=0
\end{aligned}
$$

\subsection{Embedded Generators}

Whilst single phase generators are represented as PQ loads (with opposite power sign), three phase generators are represented as three symmetrical current sources in parallel with admittance matrix $\mathbf{Y}_{\mathbf{G}}$ [20].

In order to include the choice of different reactive power outputs levels in the MILP model, $n_{\mathrm{EG}, k}$ discrete compensation levels are represented. Each level $g$ corresponds to reactive power output $Q_{k, g}^{\mathrm{EG}}$ or power factor $p f_{k, g}^{\mathrm{EG}}$, whilst active output $P_{k}^{\mathrm{EG}}$ is assumed fixed. In [13] a different MILP formulation based on the use of McCormick's envelopes is proposed.

For three-phase EGs at bus $k$ (with nodes $k_{a}, k_{b}$, and $k_{c}$ ) we write

$$
\begin{aligned}
& \mathbf{I}_{\mathrm{EG}, k}^{r e}-\sum_{g=1}^{n_{\mathrm{EG}, k}} \mathbf{I}_{k, g}^{\mathrm{EG}, r e}+\operatorname{Re}\left(\mathbf{Y}_{G} \mathbf{V}_{k}\right)=0 \\
& \mathbf{I}_{\mathrm{EG}, k}^{i m}-\sum_{g=1}^{n_{\mathrm{EG}, k}} \mathbf{I}_{k, g}^{\mathrm{EG}, i m}+\operatorname{Im}\left(\mathbf{Y}_{G} \mathbf{V}_{k}\right)=0
\end{aligned}
$$

where $\mathbf{V}_{k}$ is the triplet of voltage phasors at bus $k$; $\mathbf{I}_{\mathrm{EG}, k}^{r e}$ and $\mathbf{I}_{\mathrm{EG}, k}^{i m}$ are the triplets of the real and imaginary coordinates of the currents phasors injected by the EG in each phase of bus $k ; \mathbf{I}_{k, g}^{\mathrm{EG}, r e}$ and $\mathbf{I}_{k, g}^{\mathrm{EG}, i m}$ are the triplets corresponding to the reactive power compensation level $g$ (only those corresponding to the selected level are not null due to the following constraints).

$\forall g=1 \ldots n_{\mathrm{EG}, k}$ :

$$
\begin{gathered}
\Delta I_{k, g}^{\mathrm{EG}, r e}+M_{k, g}^{r e} u_{k, g}^{\mathrm{EG}} \leq M_{k, g}^{r e} \text { and }-\Delta I_{k, s w}^{\mathrm{EG}, r e}+M_{k, g}^{r e} u_{k, g}^{\mathrm{EG}} \leq M_{k, g}^{r e} \\
\Delta I_{k, g}^{\mathrm{EG}, i m}+M_{k, g}^{i m} u_{k, g}^{\mathrm{EG}} \leq M_{k, g}^{i m} \text { and }-\Delta I_{k, g}^{\mathrm{EG}, i m}+M_{k, g}^{i m} u_{k, g}^{\mathrm{EG}} \leq M_{k, g}^{i m}
\end{gathered}
$$




$$
\begin{gathered}
I_{\mathrm{EG}, k}^{\mathrm{min}, r e} u_{k, g}^{\mathrm{EG}} \leq I_{k, g}^{\mathrm{EG}, r e} \leq I_{\mathrm{EG}, k}^{\mathrm{max}, r e} u_{k, g}^{\mathrm{EG}} \\
I_{\mathrm{EG}, i m}^{\mathrm{min}, i m} u_{k, g}^{\mathrm{EG}} \leq I_{k, g}^{\mathrm{EG}, i m} \leq I_{\mathrm{EG}, k}^{\mathrm{max}, i m} u_{k, g}^{\mathrm{EG}}
\end{gathered}
$$

with $\sum_{g=1}^{n_{\mathrm{EG}, k}} u_{k, g}^{\mathrm{EG}}=1$. Binary variable $u_{k, g}^{\mathrm{EG}}$ is associated to each level $g . M_{k, g}^{r e}$ and $M_{k, g}^{i m}$ are tight values that do not limit $\Delta I_{k, g}^{\mathrm{EG}, r e}$ and $\Delta I_{k, g}^{\mathrm{EG}, i m}$ when $u_{k, g}^{\mathrm{EG}}=0$.

For phase a of bus $k$ (indicated as $k_{a}$ ):

$$
\begin{aligned}
& I_{k_{a}, g}^{\mathrm{EG}, r e}-\Delta I_{k_{a}, g}^{P, r e}+\Delta I_{k_{a}, g}^{\mathrm{EG}, r e}=I n_{k_{a}, g}^{\mathrm{EG}, r e} \\
& I_{k_{a}, g}^{i m}-\Delta I_{k_{a}, g}^{\mathrm{P}, i m}+\Delta I_{k_{a}, g}^{\mathrm{EG}, i m}=I n_{k_{a}, g}^{\mathrm{EG}, i m}
\end{aligned}
$$

with $\Delta I_{k_{a}, g}^{P, r e}$ and $\Delta I_{k_{a}, g}^{\mathrm{P}, i m}$ defined by, analogously to (15),

$$
\begin{aligned}
& \Delta I_{k_{a}, g}^{\mathrm{P}, r e}\left|V_{0, k}\right| \cos \left(\angle V_{k_{a}}^{0}\right)+\Delta I_{k_{a}, g}^{\mathrm{P}, i m}\left|V_{0, k}\right| \sin \left(\angle V_{k_{a}}^{0}\right)+\operatorname{In}_{k_{a}, g}^{\mathrm{EG}, r e}\left(\Delta V_{k_{1}}^{r e}\right)+ \\
& +\operatorname{In}_{k_{a}, g}^{\mathrm{EG}, i m}\left(\Delta V_{k_{1}}^{i m}\right)+\operatorname{Re}\left(\Delta \mathbf{V}_{k} \mathbf{Y}_{G} \Delta \mathbf{V}_{k}\right)_{a}=0 \\
& \Delta I_{k_{a}, g}^{\mathrm{P}, r e}\left|V_{0, k}\right| \sin \left(\angle V_{k_{a}}^{0}\right)-\Delta I_{k_{a}, g}^{\mathrm{P}, i m}\left|V_{0, k}\right| \cos \left(\angle V_{k_{a}}^{0}\right)+\operatorname{In}_{k_{a}}^{\mathrm{EG}, r e}\left(\Delta V_{k_{1}}^{i m}\right)- \\
& -\operatorname{In}_{k_{a}}^{\mathrm{EG}, i m}\left(\Delta V_{k_{1}}^{r e}\right)+\operatorname{Im}\left(\Delta \mathbf{V}_{k} \mathbf{Y}_{G} \Delta \mathbf{V}_{k}\right)_{a}=0
\end{aligned}
$$

where $\Delta \mathbf{V}_{k}$ is the variation of $\mathbf{V}_{k}$ with respect to $\mathbf{V}_{0, k} ; \Delta V_{k_{1}}^{r e}$ and $\Delta V_{k_{1}}^{\text {im }}$ indicate the positive sequence component of $\Delta \mathbf{V}_{k} ; \operatorname{In}_{k_{a}, g}^{\mathrm{EG}, r e}$ and $\operatorname{In}_{k_{a}, g}^{\mathrm{EG}, i m}$ correspond to the active and reactive power injections at compensation level $g$ and at rated voltage $V_{0, k}$ calculated by

$$
\operatorname{In}_{k_{a}, g}^{\mathrm{EG}, r e}+j \operatorname{In}_{k_{a}, g}^{\mathrm{EG}, i m}=\frac{\left(P_{k}^{\mathrm{EG}}-j Q_{k, g}^{\mathrm{EG}}\right)+\mathbf{V}_{0, k}^{*} \mathbf{Y}_{G} \mathbf{V}_{0, k}}{V_{0, k_{1}}^{*}}
$$

being $V_{0, k_{1}}$ the positive sequence phasor of $\mathbf{V}_{0, k}$ and ${ }^{*}$ the conjugate (transpose).

Current phasors $I_{k_{b}, g}^{\mathrm{EG}}$ and $I_{k_{c}, g}^{\mathrm{EG}}$ in phase b and phase c, respectively, are constrained so to obtain a three-phase positive symmetrical current source. 


\subsection{Capacitor Banks}

A binary variable $u_{k, s w}^{\mathrm{C}}$ is associated to each switch $s w$ of a bank with $n_{\mathrm{C}, k}$ capacitors connected to node $k$. Current $I_{\mathrm{C}, k}^{r e}+j I_{\mathrm{C}, k}^{i m}$ derived by the capacitor is provided by the summation of the currents associated with each switch position:

$$
I_{\mathrm{C}, k}^{r e}-\sum_{s w=1}^{n_{\mathrm{C}, k}} I_{k, s w}^{\mathrm{C}, r e}=0 \text { and } I_{\mathrm{C}, k}^{i m}-\sum_{s w=1}^{n_{\mathrm{C}, k}} I_{k, s w}^{\mathrm{C}, i m}=0
$$

At least one current $I_{k, s w}^{\mathrm{C}, r e}+j I_{k, s w}^{\mathrm{C}, i m}$ is not null due to the following constraints.

$$
\forall s w=1 \ldots n_{\mathrm{C}, k}:
$$

$$
\begin{gathered}
I_{k, s w}^{\mathrm{C}, r e} / \omega C_{k, s w}+V_{k}^{i m}+\Delta v_{k, s w}^{\mathrm{C}, r e}=0 \\
I_{k, s w}^{\mathrm{C}, m} / \omega C_{k, s w}-V_{k}^{r e}+\Delta v_{k, s w}^{\mathrm{C}, i m}=0 \\
\Delta v_{k, s w}^{\mathrm{C}, r e}+M_{k}^{r e} u_{k, s w}^{\mathrm{C}} \leq M_{k}^{r e} \text { and }-\Delta v_{k, s w}^{\mathrm{C}, r e}+M_{k}^{r e} u_{k, s w}^{\mathrm{C}} \leq M_{k}^{r e} \\
\Delta v_{k, s w}^{\mathrm{C}, i m}+M_{k}^{i m} u_{k, s w}^{\mathrm{C}} \leq M_{k}^{i m} \text { and }-\Delta v_{k, s w}^{\mathrm{C}, i m}+M_{k}^{i m} u_{k, s w}^{\mathrm{C}} \leq M_{k}^{i m} \\
I_{\mathrm{C}, k}^{\min , r e} u_{k, s w}^{\mathrm{C}} \leq I_{k, s w}^{\mathrm{C}, r e} \leq I_{\mathrm{C}, k}^{\mathrm{max}, r e} u_{k, s w}^{\mathrm{C}} \\
I_{\mathrm{C}, k}^{\min , i m} u_{k, s w}^{\mathrm{C}} \leq I_{k, s w}^{\mathrm{C}, i m} \leq I_{\mathrm{C}, k}^{\max , i m} u_{k, s w}^{\mathrm{C}}
\end{gathered}
$$

with $\sum_{s w=1}^{n_{\mathrm{C}, k}} u_{k, s w}^{\mathrm{C}} \leq 1 . M_{k}^{r e}$ and $M_{k}^{i m}$ are tight values that do not limit $\Delta v_{k, s w}^{\mathrm{C}, r e}$ and $\Delta v_{k, s w}^{\mathrm{C}, i m}$ when $u_{k, s w}^{\mathrm{C}}=0$

\subsection{Distribution Voltage Regulators}

If the internal impedance can be neglected, voltage regulators are represented by the following model that is simpler than the one adopted for transformers equipped with an OLTC (8)-(10).

$\forall t=1 \ldots n_{b, t}:$

$$
V_{h}^{r e}-m_{t} V_{k}^{r e}+\Delta v_{b, t}^{r e}=0 \text { and } V_{h}^{i m}-m_{t} V_{k}^{i m}+\Delta v_{b, t}^{i m}=0
$$

being $h$ and $k$ the nodes of the same phase at the primary and secondary side respectively, $m_{t}$ is the ratio corresponding to tap position $t$. 
Constraints (9) and (10) still apply also for this simplified model where, for each phase, $I_{b}$ refers to the current at the primary side. In order to calculate the Cartesian coordinates of the corresponding current phasor at the secondary side $\left(I_{b}^{\prime \prime}\right)$, the following constraints are added:

$$
I_{b}^{\prime \prime r e}-\sum_{t=1}^{n_{b, t}} m_{t} I_{b, t}^{r e}=0 \text { and } I_{b}^{n i m}-\sum_{t=1}^{n_{b, t}} m_{t} I_{b, t}^{i m}=0
$$

\subsection{Bus Equations}

In each node $k$ that does not belong to the slack bus the equilibrium of the currents is forced:

$$
\begin{aligned}
& \sum_{b \in B_{k}^{+}} I_{b}^{r e}-\sum_{b \in B_{k}^{-}} I_{b}^{r e}+I_{\mathrm{L}, k}^{r e}+I_{\mathrm{C}, k}^{r e}-I_{\mathrm{EG}, k}^{r e}=0 \\
& \sum_{b \in B_{k}^{+}} I_{b}^{i m}-\sum_{b \in B_{k}^{-}} I_{b}^{i m}+I_{\mathrm{L}, k}^{i m}+I_{\mathrm{C}, k}^{i m}-I_{\mathrm{EG}, k}^{i m}=0
\end{aligned}
$$

where $B_{k}$ is the set of branches $b$ connected to node $k$ (being $B_{k}^{+}$the set to the branch leaving $k$ and $B_{k}^{-}$ the set of those entering in $k$ ). If $k$ is connected to the secondary side of a distribution voltage regulator represented with the simplified model then $I_{b}^{r e}$ and $I_{b}^{i m}$ are replaced by $I_{b}^{\text {"re }}$ and $I_{b}^{\text {"im }}$ of (29).

\subsection{Bus Voltage and Branch Current Limits}

The minimum and maximum node voltage and maximum branch current constraints are represented through the description of the feasible region by means of polygons, as described in [8].

\section{Test results}

The model described in the previous section has been implemented in Matlab R2012a and solved by using IBM ILOG CPLEX V12.5 MIP on a computer with two 3.07 GHz Intel six-core processors and 48 GB of RAM, running 64-bit Windows.

Numerical tests have been carried out for the following networks adapted from IEEE test feeders:

TS1 IEEE 13 Node Test Feeder, with two additional EGs, namely a single-phase unit at bus 646 and a three-phase unit at bus 680 (Fig. 1); 
TS2 IEEE 34 Node Test Feeder with a three-phase EG unit at bus 888 (Fig. 2);

TS3 IEEE 123 Node Test Feeder, with a three-phase EG unit at node 56 and a single-phase EG unit at node 104 (Fig. 3).

In all the models, the magnetizing branches of the transformers are neglected. The capacitors banks are independently switchable on a per phase basis with one or two equal step increments if the maximum power is equal or greater than $50 \mathrm{kvar}$, respectively. $\mathbf{Y}_{\mathbf{G}}$ of the three-phase EG models is neglected. Distributed loads along a line are assumed to be concentrated at the remote line termination. The lower and upper bus voltage limits are $0.95 \mathrm{pu}$ and $1.05 \mathrm{pu}$, respectively, and the minimum power factor limit on each phase at the substation is 0.8 , whilst the current branch limits are set large enough so they are never binding the solution.

The following subsections present the results obtained for the considered test feeders by means of tables that report the optimal values of the control variables calculated by the MILP model, the number of variables (total number and number of binary variables), the number of constraints, the final relative objective gap (i.e. the difference between the best solution and its best lower bound divided by the best solution value) and the computer time spent to obtain the solution. In parenthesis, the tables indicate the percentage differences between the MILP results and those obtained by the corresponding power flow (PF) calculation (the EMTP-rv 2.5 software is used). These differences provide an indication of the influence of the adopted linear approximation on the accuracy of the results obtained by using the MILP model.

\subsection{TS1}

The slack bus is at the primary side of the 5 MVA D-Y substation transformer with voltage equal to $V_{\mathrm{s}}=115 \mathrm{kV}$. This transformer is equipped with an OLTC with \pm 12 tap increments of $1.25 \%$ with rated ratio equal to $115 / 4.16 \mathrm{kV}$. The fixed ratio of the $\mathrm{Y}-\mathrm{Y}$ transformer feeding bus 634 is $4.16 / 0.48 \mathrm{kV}$. One-phase switched capacitor bank with maximum power of $100 \mathrm{kvar}$ is connected at node $611 \mathrm{c}$ and a three-phase bank at bus 675 (maximum power of 200 kvar at each phase). The two additional EGs are: a $400 \mathrm{~kW}$ single-phase unit at node $646 \mathrm{~b}$ and a $1200 \mathrm{~kW}$ three-phase unit at bus 680 . The EGs have the 
possibility to control the reactive output in \pm 12 discrete levels with a minimum power factor limit of 0.7 .

Table IV shows the results obtained with and without the presence of EGs for two different load levels: normally loaded (i.e. as in IEEE Test Feeder data) and light-loaded (i.e. obtained by multiplying each load demand by 0.5$)$.

Without EGs, the system without regulation (i.e. with all capacitors disconnected and OLTC in the 0 tap position) has

- $\quad$ at normal load: losses $=211.01 \mathrm{~kW}$, minimum bus voltage $=0.804 \mathrm{pu}($ node $611 \mathrm{c})$ and $\min$ power factor at the substation $=0.71$ (phase $b)$;

- $\quad$ at light load: losses $=45.9 \mathrm{~kW}$, $\min$ voltage $=0.911 \mathrm{pu}($ node $611 \mathrm{c})$ and $\min$ power factor $=$ 0.77 (phase b).

With the action of the OLTC and capacitor banks, the calculated operating condition slightly violates the $\pm 5 \%$ voltage limits as well as the minimum power factor constraint (the relevant penalties are added to the objective function value) whilst all the constraints are met at light load. Losses are reduced by around a quarter in both load conditions.

With the EGs, the system without regulation (i.e. with all capacitors disconnected, OLTC in the 0 tap position and EG at unity power factor) has

- $\quad$ at normal load: losses $=129.7 \mathrm{~kW}$, min voltage $=0.817 \mathrm{pu}($ node $611 \mathrm{c})$, max voltage $=0.982$ $\mathrm{pu}$ (node 680b) and min power factor at the substation $=0.35$ (phase $\mathrm{b}$ );

- $\quad$ at light load: losses $=29.9 \mathrm{~kW}$, min voltage $=0.92 \mathrm{pu}($ node $611 \mathrm{c})$, max voltage $=1.00 \mathrm{pu}$ $(646 b)$ and $\min$ power factor $=0.18$ (phase $b)$.

Losses are significantly reduced in both load conditions thanks to the action of the OLTC, of capacitor banks and of EG regulation. At normal load, the power factor on phase b of slack bus is lower than 0.8 and the maximum voltage limit is exceeded at node $680 \mathrm{~b}$, whilst at light load the power factor constraint is violated on phase $\mathrm{b}$ and $\mathrm{c}$ (the relevant penalties are added to the objective function value). Although the internal $\mathbf{Y}_{\mathbf{G}}$ matrix is neglected, due to the network imbalance, different active and reactive powers are obtained on each phase of the three-phase EG at bus 680: 416, 386, $397 \mathrm{~kW}$ and 
380, 456, 375 kvar at normal load whilst 433, 368, $394 \mathrm{~kW}$ and 400, 433, 373 at light load on phase a, phase $\mathrm{b}$ and phase $\mathrm{c}$, respectively.

\section{2. $T S 2$}

The slack bus is at the primary side of the 2.5 MVA D-Y substation transformer with voltage equal to $V_{\mathrm{s}}=69 \mathrm{kV}$. This transformer is assumed at fixed ratio equal to 2.56 . There are two $4.16 / 4.16 \mathrm{kV}$ distribution voltage regulators connected before nodes 850 and 832 , each enabling \pm 12 tap increments of $1.25 \%$ at the secondary side. Two three-phase capacitor banks are connected to bus 844 (with maximum 100 kvar per phase) and to bus 848 (with maximum 150 kvar per phase), respectively. The additional EG at bus 888 is a $500 \mathrm{~kW}$ three-phase unit with the possibility to control the reactive output in \pm 6 discrete levels with a minimum power factor limit of 0.7 .

Table V shows the results obtained without and with the EG.

Without the EG, the system without regulation (i.e. with all capacitors disconnected and all OLTCs in the 0 tap position) has losses $=298.57 \mathrm{~kW}$, minimum bus voltage $=0.743 \mathrm{pu}$ (node $890 \mathrm{a}$ ), total load equal to $1.502 \mathrm{MW}$, min power factor at the substation $=0.84$ (phase $b$ ). With the action of the distribution voltage regulators and capacitor banks, the calculated operating condition slightly violates the $\pm 5 \%$ voltage limits with improved power factors. Due to the voltage dependence of the loads that causes a $20 \%$ increase of the load consumption, the power loss rises by $8.85 \%$.

With the EG and without regulation (i.e. with all capacitors disconnected, OLTC in the 0 tap position and $\mathrm{EG}$ at unity power factor) the system has losses $=188.4 \mathrm{~kW}$, minimum bus voltage $=0.834 \mathrm{pu}$ (node $890 \mathrm{a}$ ), total load equal to $1.588 \mathrm{MW}$, min power factor at the substation $=0.77$ (phase $\mathrm{c}$ ). With the action of the voltage regulators and capacitor banks, the calculated operating condition only slightly violates the $+5 \%$ voltage limit at node $800 \mathrm{c}$. The load rises by $13 \%$ whilst the power loss increases less than $1 \%$.

\section{3. $T S 3$}

The slack bus voltage is equal to $V_{\mathrm{s}}=115 \mathrm{kV}$. The 5 MVA D-Y OLTC substation transformer has rated ratio equal to $115 / 4.16 \mathrm{kV}$ with \pm 12 tap increments of $1.25 \%$. Moreover there is a three-phase 
4.16/4.16 kV distribution voltage regulator connected before node 67 with \pm 12 tap increments of $1.25 \%$. The other two distribution voltage regulators and the 4.16/0.48 kV transformer shown in Fig. 3 (connected between buses 25-26, 9-14, 61-610, respectively) are considered at fixed ratio. A threephase capacitor bank is connected to bus 83 (with maximum 200 kvar per phase). Three single-phase capacitor banks are connected to node $88 \mathrm{a}, 90 \mathrm{~b}$, and $92 \mathrm{c}$ (with maximum $50 \mathrm{kvar}$ ). The two additional EGs are a 1.2 MW three-phase unit at bus 56 and a $400 \mathrm{~kW}$ single-phase unit at node $104 \mathrm{c}$ both allowing \pm 6 discrete reactive power levels with a minim power factor limit of 0.85 . Also the results obtained for TS3 without and with the EGs are shown in Table V. Without EGs, the system without regulation (i.e. with all capacitors disconnected and OLTCs in the 0 tap position) has losses $=152.7 \mathrm{~kW}$, minimum bus voltage $=0.85 \mathrm{pu}($ node $114 \mathrm{a})$, total load equal to $3.269 \mathrm{MW}$, min power factor at the substation $=0.76$ (phase $b$ ). With the action of the voltage regulators and capacitor banks, the calculated operating condition meets all the constraints. Although a roughly $5 \%$ load increase, power loss decreases by $9 \%$. With the EGs and without regulation (i.e. with all capacitors disconnected, OLTC in the 0 tap position and EGs at unity power factor) the system has losses = $102.46 \mathrm{~kW}$, minimum bus voltage $=0.85 \mathrm{pu}$ (node $114 \mathrm{a}$ ), total load equal to $3.3 \mathrm{MW}$, min power factor at the substation $=0.53$ (phase $\mathrm{c}$ ). With the action of the voltage regulators and capacitor banks, the calculated operating condition meets all the constraints, load increases by $4.7 \%$ and the power loss decreases by nearly $30 \%$.

\section{Conclusions}

The paper presents a MILP model for the solution of the VVO in unbalanced three-phase distribution feeders. The model includes the specific characteristics of the components and takes the usual operating constraints into account.

The method has been applied to three different IEEE test feeders with OLTC transformers, distribution voltage regulators, switchable capacitor banks, and EGs. The comparison between the obtained results and those provided by the three-phase PF calculations (for the optimal configuration) shows that the achieved accuracy is adequate. 
As expected, the computational effort significantly increases with respect to a previously presented

MILP model that assumes a balanced network. However, with acceptable CPU time, accurate results

are obtained also for medium size feeders.

\section{Acknowledgment}

This paper is a revised and extended version of contribution [22] presented at the 18th Power Systems Computation Conference (PSCC'14) 2014. We would like to thank the participants for their helpful comments and suggestions. This research was supported in part by the Italian Ministry of Economic Development in the framework of CERSE research project SMARTGEN and by ENIAC JU/CALL 2011-1/296131 E2SG “Energy to smart grid”. IBM ILOG CPLEX Optimization Studio has been used thanks to the IBM Academic Initiative.

\section{References}

[1] S. Rahimi, M. Marinelli, and F. Silvestro, "Evaluation of requirements for volt/var control and optimization function in distribution management systems," in Proc. of 2012 IEEE Int. Energy Conf. and Exhibition (ENERGYCON), 2012, pp. 331-336.

[2] M. J. Krok and S. Genc, "A coordinated optimization approach to Volt/VAr control for large power distribution networks," in Proc. of the 2011 American Control Conference, 2011, pp. $1145-1150$.

[3] I. Roytelman, B. K. Wee, and R. L. Lugtu, "Volt/var control algorithm for modern distribution management system," IEEE Trans. Power Syst., vol. 10, no. 3, pp. 1454-1460, 1995.

[4] K. Turitsyn, P. Šulc, S. Backhaus, and M. Chertkov, "Options for control of reactive power by distributed photovoltaic generators," Proc. IEEE, vol. 99, no. 6, pp. 1063-1073, Jun. 2011.

[5] E. A. Paaso, Y. Liao, and A. M. Cramer, "Formulation and solution of distribution system voltage and VAR control with distributed generation as a mixed integer non-linear programming problem," Electr. Power Syst. Res., vol. 108, pp. 164-169, 2014.

[6] W. H. Kersting, "The whys of distribution system analysis," IEEE Ind. Appl. Mag., vol. 17, no. 5, pp. 59-65, Sep. 2011.

[7] S. Paudyal, C. A. Cañizares, and K. Bhattacharya, "Optimal operation of distribution feeders in smart grids," IEEE Trans. Ind. Electron., vol. 58, no. 10, pp. 4495-4503, 2011.

[8] A. Borghetti, "Using mixed integer programming for the volt/var optimization in distribution feeders," Electr. Power Syst. Res., vol. 98, pp. 39-50, May 2013.

[9] A. Lodi, "Mixed integer programming computation," in 50 Years of Integer Programming 1958-2008, M. Jünger, T. M. Liebling, D. Naddef, G. L. Nemhauser, W. R. Pulleyblank, G. Reinelt, G. Rinaldi, and L. A. Wolsey, Eds. Berlin, Heidelberg: Springer Berlin Heidelberg, 2010, pp. 619-645.

[10] A. Borghetti, "A mixed-integer linear programming approach for the computation of the minimum-losses radial configuration of electrical distribution networks," IEEE Trans. Power Syst., vol. 27, no. 3, pp. 1264-1273, 2012. 
[11] J. F. Franco, M. J. Rider, M. Lavorato, and R. Romero, "A mixed-integer LP model for the reconfiguration of radial electric distribution systems considering distributed generation," Electr. Power Syst. Res., vol. 97, pp. 51-60, 2013.

[12] J. F. Franco, M. J. Rider, M. Lavorato, and R. Romero, "A mixed-integer LP model for the optimal allocation of voltage regulators and capacitors in radial distribution systems," Int. J. Electr. Power Energy Syst., vol. 48, pp. 123-130, 2013.

[13] R. S. Ferreira, C. L. T. Borges, and M. V. F. Pereira, "A flexible mixed-integer linear programming approach to the AC optimal power flow in distribution systems," IEEE Trans. Power Syst., vol. 29, no. 5, pp. 2447-2459, Sep. 2014.

[14] R. P. O'Neill, A. Castillo, and M. B. Cain, "The IV formulation and linear approximations of the AC optimal power flow problem," FERC staff technical paper, OPF paper 2, 2012.

[15] C. Coffrin and P. Van Hentenryck, "A linear-programming approximation of AC power flows," INFORMS J. Comput., vol. 26, no. 4, pp. 718-734, Nov. 2014.

[16] M. Laughton, "Analysis of unbalanced polyphase networks by the method of phase coordinates. Part 1: System representation in phase frame of reference," Proc. Inst. Electr. Eng., vol. 115 , no. 8, p. 1163, 1968.

[17] Y. Cao, Y. Tan, C. Li, and C. Rehtanz, "Chance-constrained optimization-based unbalanced optimal power flow for radial distribution networks," IEEE Trans. Power Deliv., vol. 28, no. 3 , pp. 1855-1864, Jul. 2013.

[18] "IEEE PES distribution test feeders." [Online]. Available: http://www.ewh.ieee.org/soc/pes/dsacom/testfeeders/.

[19] H. Smolleck and R. Shoults, "A straightforward method for incorporating mutually-coupled circuits into the bus admittance matrix using the concept of artificial branches," IEEE Trans. Power Syst., vol. 5, no. 2, pp. 486-491, 1990.

[20] T. Chen, M. Chen, T. Inoue, P. Kotas, and E. A. Chebli, "Three-phase cogenerator and transformer models for distribution system analysis," IEEE Trans. Power Deliv., vol. 6, no. 4, pp. 1671-1681, 1991.

[21] J. Peralta, F. de León, and J. Mahseredjian, "Unbalanced multiphase load-flow using a positive-sequence load-flow program," IEEE Trans. Power Syst., vol. 23, no. 2, pp. 469-476, 2008.

[22] A. Borghetti, F. Napolitano, and C. A. Nucci, "Volt/var optimization of unbalanced distribution feeders via mixed integer linear programming," in Proc. of 18th Power Systems Computation Conference, 2014, pp. 1-7. 


\section{Figure captions}

Fig. 1 Test system TS1. The different thickness of the segments represents power lines with different number of conductors, namely: three phase lines (the thickest ones), two phase lines and single phase lines (the thinnest ones). Figure adapted from [18].

Fig. 2 Test system TS2. Figure adapted from [18].

Fig. 3 Test system TS3. Figure adapted from [18].

\section{Table titles}

TABLE I - CONNECTION TABLE FOR THREE-PHASE LINES.

TABLE II - CONNECTION TABLE FOR GROUNDED WYE - GROUNDED WYE TRANSFORMER.

TABle III - CONNECTION TABLE FOR DELTA - GROUNDED WYE TRANSFORMER.

TABLE IV - MILP SOLUTIONS FOR TS1 (IN PARENTHESIS THE PERCENTAGE DEVIATION WITH RESPECT TO THE PF RESULTS).

TABLE V - MILP SOLUTIONS FOR TS2 AND TS3 (IN PARENTHESIS THE PERCENTAGE DEVIATION WITH RESPECT TO THE PF RESULTS). 


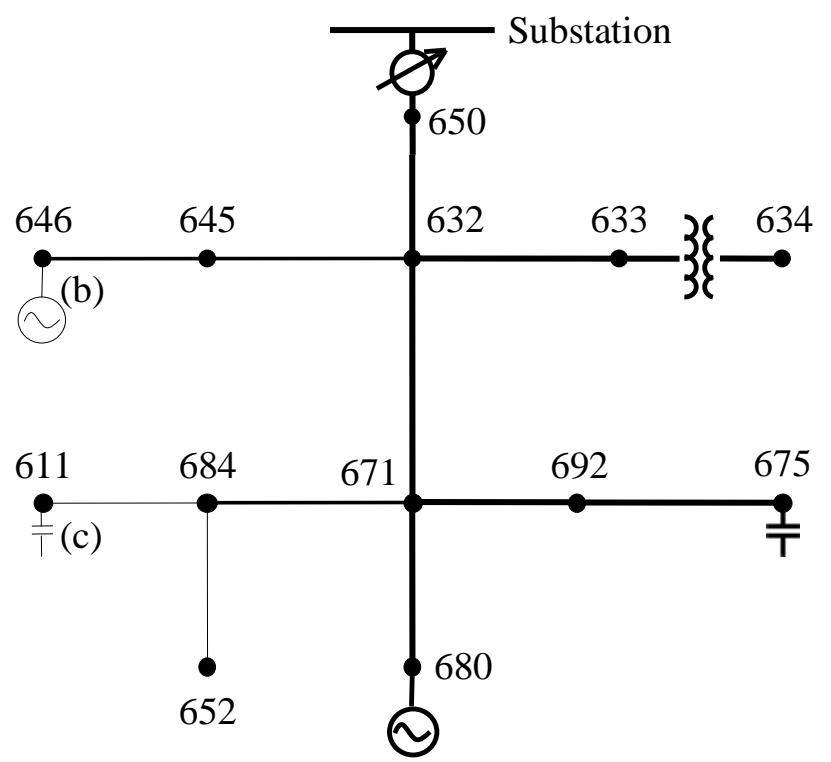

Fig. 1. Test system TS1. The different thickness of the segments represents power lines with different number of conductors, namely: three phase lines (the thickest ones), two phase lines and single phase lines (the thinnest ones). Figure adapted from [18]. 


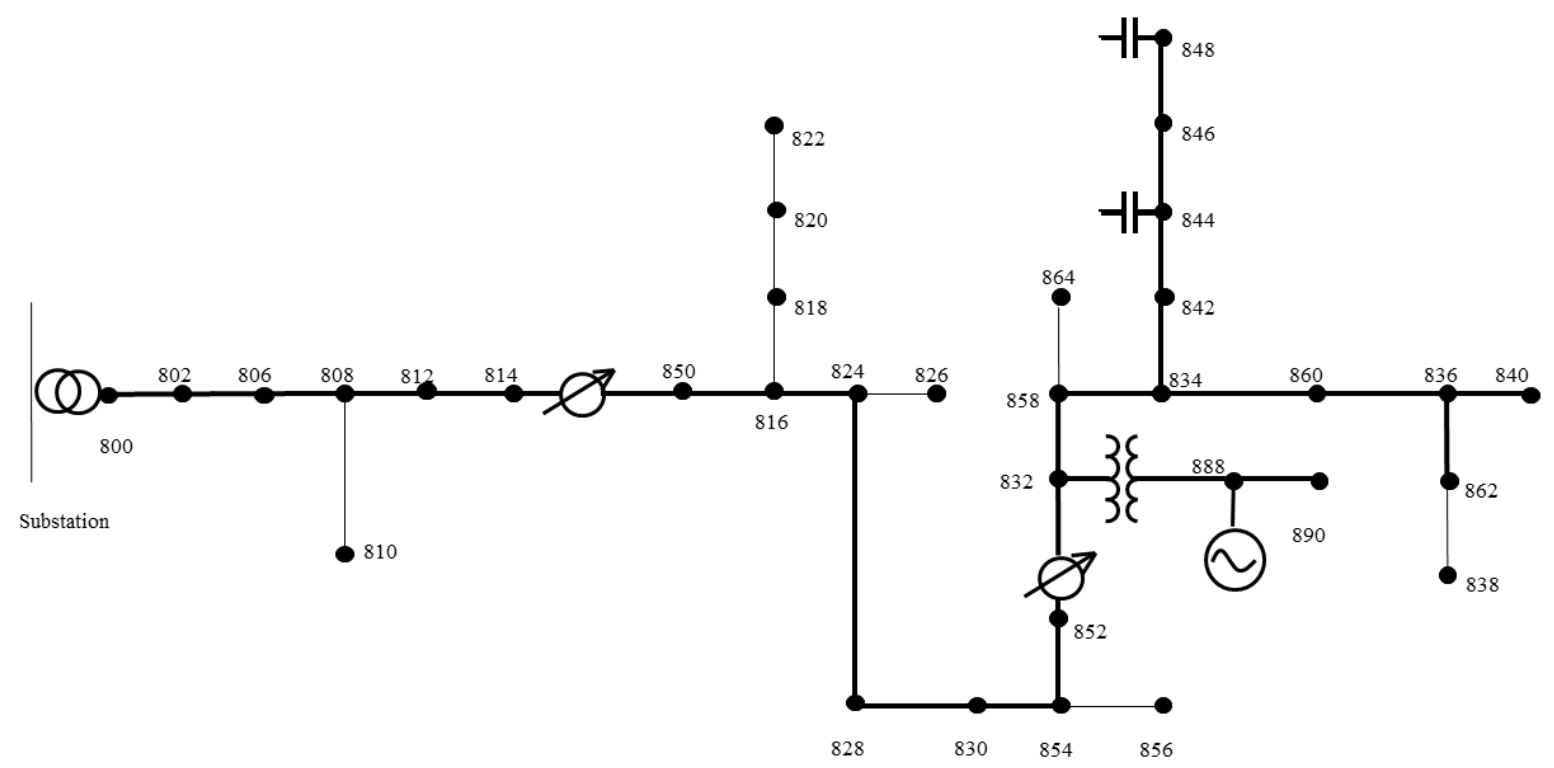

Fig. 2. Test system TS2. Figure adapted from [18]. 


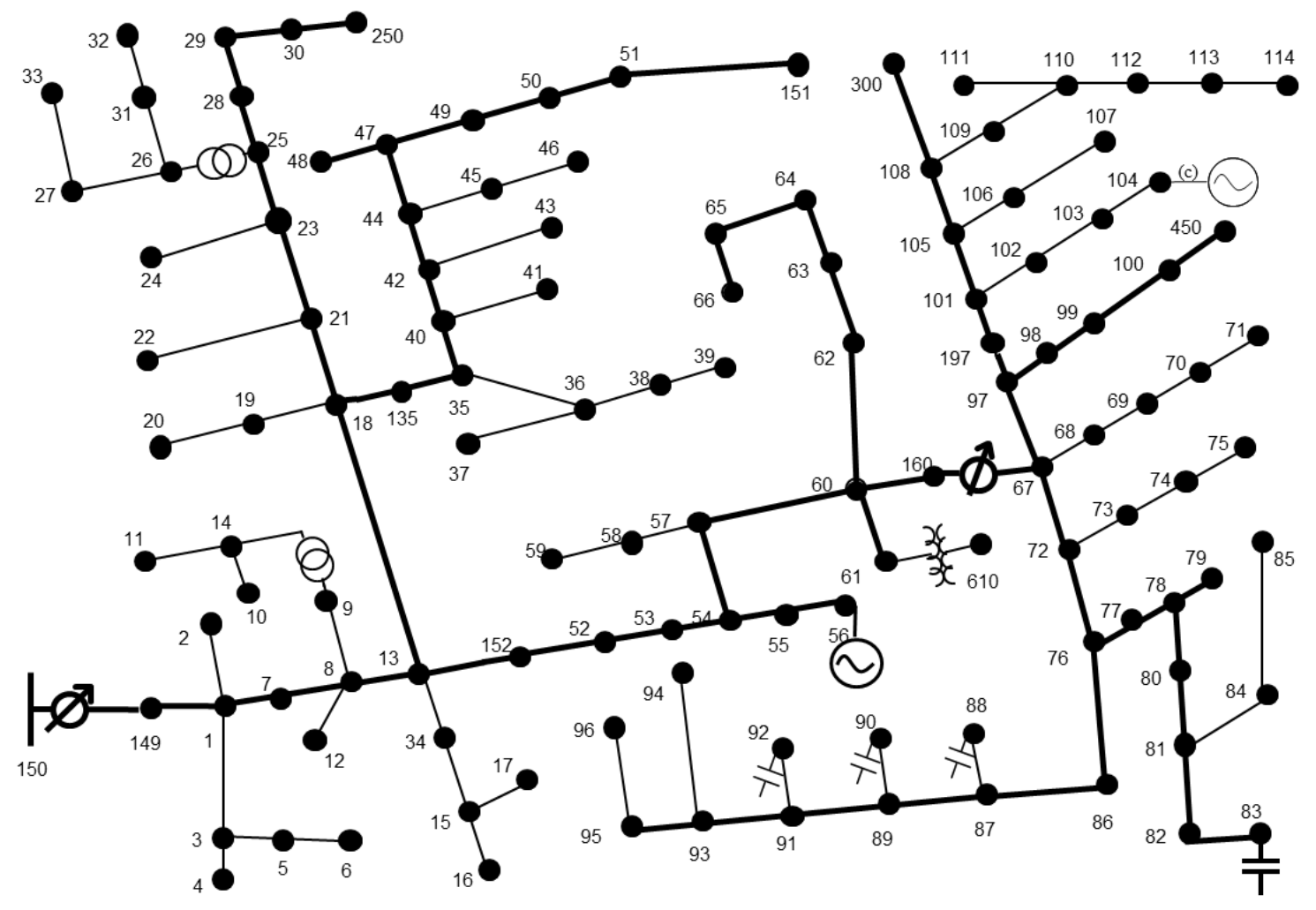

Fig. 3. Test system TS3. Figure adapted from [18]. 
TABLE I - CONNECTION TABLE FOR THREE-PHASE LINES

\begin{tabular}{c|c}
\hline \hline admittances & between nodes \\
\hline $\operatorname{diag}(\mathbf{Y}) \quad$ with $\quad \mathbf{Y}=\mathbf{Z}^{-1}$ & A-a, B-b, C-c \\
\hline $0.5 \operatorname{sum}(B(i,:)) \quad i=1,2,3$ & $\begin{array}{c}\text { A-N, B-N, C-N } \\
\text { equal to a-n, b-n, c-n }\end{array}$ \\
\hline$Y(i, j) \quad i, j=1,2,3 \quad i \neq j$ & A-b, A-c, B-a, B-c, C-a, C-b \\
\hline$-(Y(i, j)+j 0.5 B(i, j))$ & $\begin{array}{c}\text { A-B, B-C, A-C } \\
\text { equal to a-b, b-c, a-c }\end{array}$ \\
\hline \hline
\end{tabular}


TABLE II - CONNECTION TABLE FOR GROUNDED WYE - GROUNDED WYE TRANSFORMER.

\begin{tabular}{c|l}
\hline \hline Admittances & between nodes \\
\hline$y_{t} m$ with $y_{t}=\frac{1}{r_{t}+j x_{t}}$ & A-a, B-b, C-c \\
\hline$y_{t}(1-m)+y_{0}$ & A-N, B-N, C-N \\
\hline$y_{t} m(m-1)$ & a-n, b-n, c-n \\
\hline \hline
\end{tabular}


TABLE III - CONNECTION TABLE FOR DELTA - GROUNDED WYE TRANSFORMER.

\begin{tabular}{c|c}
\hline \hline Admittances & between nodes \\
\hline$y_{t} m / \sqrt{3}$ & A-a, B-b, C-c \\
\hline$y_{0}$ & A-N, B-N, C-N \\
\hline$y_{t} / 3$ & A-B, B-C, C-A \\
\hline$-y_{t} m / \sqrt{3}$ & A-b, B-c, C-a \\
\hline$y_{t} m^{2}$ & a-n, b-n, c-n \\
\hline \hline
\end{tabular}


TABLE IV - MILP SOLUTIONS FOR TS1 (IN PARENTHESIS THE PERCENTAGE DEVIATION WITH RESPECT TO THE PF RESULTS).

\begin{tabular}{|c|c|c|c|c|}
\hline & \multicolumn{2}{|c|}{ without EG } & \multicolumn{2}{|c|}{ with EG } \\
\hline & normal load & light load & normal load & light load \\
\hline $\begin{array}{l}\text { Cap. steps at nodes } \\
611_{\mathrm{c}}, 675_{\mathrm{abc}}\end{array}$ & $2,2,0,2$ & $2,2,1,2$ & $2,2,0,2$ & $0,2,0,0$ \\
\hline OLTC tap & -7 & 0 & -2 & 1 \\
\hline $\begin{array}{c}\text { EG } Q \text { steps } \\
\text { at bus } 646,680\end{array}$ & & & 0,12 & $-8,12$ \\
\hline losses & $161.79 \mathrm{~kW}(3.3 \%)$ & $\begin{array}{c}34.94 \mathrm{~kW} \\
(0.83 \%)\end{array}$ & $\begin{array}{l}70.22 \mathrm{~kW} \\
(2.47 \%)\end{array}$ & $\begin{array}{c}32.25 \mathrm{~kW} \\
(0.34 \%)\end{array}$ \\
\hline \multirow{2}{*}{$\begin{array}{c}\text { min voltage } \\
\text { elsewhere than slack bus }\end{array}$} & $\begin{array}{c}0.9536 \mathrm{pu} \\
(-0.22 \%)\end{array}$ & $\begin{array}{c}0.9503 \mathrm{pu} \\
(0.035 \%)\end{array}$ & $\begin{array}{c}0.9514 \mathrm{pu} \\
(0.008 \%)\end{array}$ & $\begin{array}{l}0.9509 \mathrm{pu} \\
(0.01 \%)\end{array}$ \\
\hline & at node $611_{c}$ & at node $652_{\mathrm{a}}$ & at node $634_{c}$ & at node $611_{c}$ \\
\hline \multirow{2}{*}{$\begin{array}{c}\text { max voltage } \\
\text { elsewhere than slack bus }\end{array}$} & $\begin{array}{c}1.056 \mathrm{pu} \\
(-0.039 \%)\end{array}$ & $\begin{array}{c}0.9886 \mathrm{pu} \\
(0.006 \%)\end{array}$ & $\begin{array}{l}1.0552 \mathrm{pu} \\
(0.058 \%)\end{array}$ & $\begin{array}{l}1.0477 \mathrm{pu} \\
(-0.01 \%)\end{array}$ \\
\hline & at node $650_{b}$ & at node $650_{c}$ & at node $680_{\mathrm{b}}$ & at node $680_{a}$ \\
\hline tot. active load & 3.507 MW (1.59\%) & $\begin{array}{c}1.723 \mathrm{MW} \\
(0.51 \%)\end{array}$ & $\begin{array}{l}3.486 \mathrm{MW} \\
(0.8 \%)\end{array}$ & $\begin{array}{c}1.733 \mathrm{MW} \\
(0.06 \%)\end{array}$ \\
\hline tot. reactive load & $\begin{array}{l}2.096 \mathrm{Mvar} \\
(-0.12 \%)\end{array}$ & $\begin{array}{l}1.033 \mathrm{Mvar} \\
(-0.53 \%)\end{array}$ & $\begin{array}{l}2.095 \text { Mvar } \\
(-0.05 \%)\end{array}$ & $\begin{array}{l}\text { 1.053 Mvar } \\
(-0.11 \%)\end{array}$ \\
\hline EG tot. active injection & & & $\begin{array}{l}1.605 \mathrm{MW} \\
(0.31 \%)\end{array}$ & $\begin{array}{c}1603 \mathrm{~kW} \\
(0.2 \%)\end{array}$ \\
\hline $\begin{array}{l}\text { EG tot. reactive } \\
\text { injection }\end{array}$ & & & $\begin{array}{l}1.230 \mathrm{Mvar} \\
(0.48 \%)\end{array}$ & $\begin{array}{l}924 \mathrm{kvar} \\
(0.01 \%)\end{array}$ \\
\hline$P$ at slack bus & $3.668 \mathrm{MW}(1.67 \%)$ & $\begin{array}{l}1.758 \mathrm{MW} \\
(0.52 \%)\end{array}$ & $\begin{array}{l}1.952 \mathrm{MW} \\
(1.27 \%)\end{array}$ & $\begin{array}{l}162 \mathrm{~kW} \\
(-1.19 \%)\end{array}$ \\
\hline$Q$ at slack bus & 2.298 Mvar (1.08\%) & $\begin{array}{l}0.617 \text { Mvar } \\
(-0.73 \%)\end{array}$ & $\begin{array}{l}647 \text { kvar } \\
(-0.18 \%)\end{array}$ & $\begin{array}{l}-2 \text { kvar } \\
(-46.5 \%)\end{array}$ \\
\hline$p f$ at slack bus $(\mathrm{a}, \mathrm{b}, \mathrm{c})$ & $0.85,0.78,0.89$ & $0.95,0.89,0.98$ & $0.96,0.74,1.00$ & $0.90,0.43,0.78$ \\
\hline no. of variables & \multicolumn{2}{|c|}{1520 (237 binary) } & \multicolumn{2}{|c|}{2182 (289 binary) } \\
\hline no. of constraints & \multicolumn{2}{|c|}{2878 (899 equality) } & \multicolumn{2}{|c|}{4092 (1313 equality) } \\
\hline obj. function & $5.1310^{3}$ & $1.7610^{3}$ & $4.2310^{3}$ & $2.9910^{3}$ \\
\hline relative obj. gap & 0 & 0 & $9.4110^{-5}$ & 0 \\
\hline CPU time & $2.05 \mathrm{~s}$ & $1.07 \mathrm{~s}$ & $37.59 \mathrm{~s}$ & 54.28 \\
\hline
\end{tabular}


TABLE V - MILP SOLUTIONS FOR TS2 AND TS3 (IN PARENTHESIS THE PERCENTAGE DEVIATION WITH RESPECT TO THE PF RESULTS).

\begin{tabular}{|c|c|c|c|c|}
\hline & \multicolumn{2}{|c|}{ without EG } & \multicolumn{2}{|c|}{ with EG } \\
\hline & $\mathrm{TS} 2$ & TS3 & TS2 & TS3 \\
\hline Cap. Steps & $\begin{array}{l}844_{\mathrm{abc}}: 2,2,0 \\
848_{\mathrm{abc}}: 2,0,2\end{array}$ & $\begin{array}{c}83_{\text {abc }}: 2,0,1 \\
88_{\mathrm{a}}: 1,90_{\mathrm{b}}: 0,92_{\mathrm{c}}: 0\end{array}$ & $\begin{array}{l}844_{\mathrm{abc}}: 2,0,0 \\
848_{\mathrm{abc}}: 0,0,0\end{array}$ & $\begin{array}{c}83_{\mathrm{abc}}: 2,1,1 \\
88_{\mathrm{a}}: 1,90_{\mathrm{b}}: 0,92_{\mathrm{c}}: 0\end{array}$ \\
\hline OLTC taps & $\begin{array}{l}\text { 850: }-4 \\
832:-8\end{array}$ & $\begin{array}{c}\text { 149: }-1 \\
67:-1\end{array}$ & $\begin{array}{l}\text { 850: }-2 \\
832:-6\end{array}$ & $\begin{array}{l}\text { 149: }-2 \\
67:-2\end{array}$ \\
\hline EG $Q$ steps & & & 2 & $\begin{array}{l}56_{\mathrm{abc}}: 6 \\
104_{\mathrm{c}}: 0\end{array}$ \\
\hline losses & $329.7 \mathrm{~kW}(1.43 \%)$ & $\begin{array}{c}140.4 \mathrm{~kW} \\
(1.17 \%)\end{array}$ & $\begin{array}{c}190.7 \mathrm{~kW} \\
(0.69 \%)\end{array}$ & $\begin{array}{l}73.3 \mathrm{~kW} \\
(0.67 \%)\end{array}$ \\
\hline $\begin{array}{l}\text { min voltage } \\
\text { elsewhere than } \\
\text { slack bus }\end{array}$ & $\begin{array}{c}0.9350 \mathrm{pu} \\
(-0.28 \%) \\
\text { at node } 890_{\mathrm{c}}\end{array}$ & $\begin{array}{c}0.9505 \mathrm{pu} \\
(-0.03 \%) \\
\text { at node } 66_{\mathrm{c}} \\
\end{array}$ & $\begin{array}{c}0.9525 \mathrm{pu} \\
(-0.65 \%) \\
\text { at node } 890_{\mathrm{a}}\end{array}$ & $\begin{array}{c}0.9489 \mathrm{pu} \\
(-0.02 \%) \\
\text { at node } 160_{\mathrm{a}}\end{array}$ \\
\hline $\begin{array}{l}\text { max voltage } \\
\text { elsewhere than } \\
\text { slack bus }\end{array}$ & $\begin{array}{c}1.0552 \mathrm{pu} \\
(-0.14 \%) \\
\text { at node } 832_{\mathrm{a}}\end{array}$ & $\begin{array}{c}1.0140 \mathrm{pu} \\
(-0.002) \\
\text { at node } 149_{\mathrm{b}}\end{array}$ & $\begin{array}{c}1.0513 \mathrm{pu} \\
(-0.05 \%) \\
\text { at node } 800_{\mathrm{c}}\end{array}$ & $\begin{array}{c}1.0367 \mathrm{pu} \\
(0.03 \%) \\
\text { at node } 300_{\mathrm{b}}\end{array}$ \\
\hline tot. active load & $1.817 \mathrm{MW}(0.43 \%)$ & $\begin{array}{c}3.447 \mathrm{MW} \\
(0.77 \%)\end{array}$ & $\begin{array}{c}1.795 \mathrm{MW} \\
(0.098 \%)\end{array}$ & $\begin{array}{c}3.469 \mathrm{MW} \\
(0.33 \%)\end{array}$ \\
\hline tot. reactive load & 1.079 Mvar (0.06\%) & $\begin{array}{c}1.873 \text { Mvar } \\
(-0.26 \%)\end{array}$ & $\begin{array}{c}\text { 1.078 Mvar } \\
(0.01 \%)\end{array}$ & $\begin{array}{l}\text { 1.9 Mvar } \\
(-0.03 \%)\end{array}$ \\
\hline $\begin{array}{c}\text { EG tot. active } \\
\text { injection }\end{array}$ & & & $\begin{array}{l}500 \mathrm{~kW} \\
(-0.05 \%) \\
\end{array}$ & $\begin{array}{c}1.602 \mathrm{MW} \\
(0.12 \%)\end{array}$ \\
\hline $\begin{array}{c}\text { EG tot. reactive } \\
\text { injection }\end{array}$ & & & $\begin{array}{c}245 \mathrm{kvar} \\
(1.1 \%)\end{array}$ & $\begin{array}{l}744 \mathrm{kvar} \\
(0.04 \%)\end{array}$ \\
\hline$P$ at slack bus & $2.147 \mathrm{MW}(0.58 \%)$ & $\begin{array}{c}3.588 \mathrm{MW} \\
(0.79 \%) \\
\end{array}$ & $\begin{array}{c}1.486 \mathrm{MW} \\
(0.22 \%)\end{array}$ & $\begin{array}{c}1.940 \mathrm{MW} \\
(0.5 \%)\end{array}$ \\
\hline$Q$ at slack bus & $753 \operatorname{kvar}(1.32 \%)$ & $\begin{array}{c}2.026 \mathrm{Mvar} \\
(0.06 \%)\end{array}$ & $\begin{array}{l}765 \text { kvar } \\
(0.55 \%)\end{array}$ & $\begin{array}{l}909 \mathrm{kvar} \\
(0.09 \%)\end{array}$ \\
\hline $\begin{array}{c}p f \text { at slack bus } \\
(\mathrm{a}, \mathrm{b}, \mathrm{c})\end{array}$ & $0.97,0.93,0.92$ & $0.91,0.82,0.87$ & $0.92,0.88,0.86$ & $0.98,0.85,0.83$ \\
\hline no. of variables & 3531 (350 binary) & 7672 (563 binary) & 3787 (364 binary) & 8022 (591 binary) \\
\hline no. of constraints & 6053 (2377 equality) & 10981 (5828 equality) & $\begin{array}{c}6532(2544 \\
\text { equality })\end{array}$ & 11619 (6050 equality) \\
\hline obj. function & $7.5210^{3}$ & $3.5910^{3}$ & $1.6610^{3}$ & $1.9410^{3}$ \\
\hline relative obj. gap & $4.1210^{-5}$ & 0 & $9.5510^{-5}$ & $9.9810^{-5}$ \\
\hline CPU time & $214 s$ & $42.9 \mathrm{~s}$ & $474 \mathrm{~s}$ & $388 \mathrm{~s}$ \\
\hline
\end{tabular}

